\title{
Biotechnology and Epilepsy Patient
}

\author{
Jitender Chaturvedi* and Aditya Patil \\ Department of Neurosurgery, AIIMS, Rishikesh, India
}

Received: 制 June 15, 2018; Published: 制July 20, 2018

*Corresponding author: Jitender Chaturvedi, Assistant Professor, Department of Neurosurgery, All India Institute of Medical Sciences, Rishikesh, Uttarakhand, India, Tel: +91 8700001758; Email: Jitender.nsurg@aiimsrishikesh.edu.in

\begin{abstract}
Management of patients suffering from Drug Resistant Epilepsy has changed dramatically over last few decades. Neurologists and Neurosurgeons of current generation have an advantage over past generations to have dramatically improved biotechnology to help them managing these patients. Recently, biotechnology has provided us with mobile health \& wearable devices to early \& promptly detect the seizures in ambulatory patients during their routine activities. This is an edge; which neuroscientists were deprived of in the past.
\end{abstract}

Abbreviations: AEDs: Antiepileptic Drugs; DRE: Drug Resistant Epilepsy; V-EEG: Video-EEG; EMG: Electromyography; SUDEP: Sudden Unexpected Death in Epilepsy

\section{Introduction}

Epilepsy is a brain disorder characterized by recurrent unprovoked seizures which occurs due to abnormal excessive electrical activity in the brain. This in turn is often reported by the patient and the accompanying persons. Commonly, it is also called as fits or seizures. Seizures can occur with or without impairment of consciousness and it depend on which part of the brain is affected in epilepsy. Approximately 50 million people in the world suffer from epilepsy, of whom $80 \%$ live in resource restricted countries. Patients are prescribed antiepileptic drugs (AEDs) for seizure control and a good response to medicines is noted in up to $70-75 \%$ of patients. However, in about $25 \%$ of patients, seizures are not controlled even after using the prescribed and appropriate dosages of more than one AEDs. These patients are known to have Drug Resistant Epilepsy (DRE). Worldwide, technology is expanding at an exponential rate, like never before. We all have witnessed how this cut-edge technology has had a definite and crucial impact even in day to day life of common man. Similarly, there has been a constant \& remarkable improvement in management of neurosurgical patients as well, on account of this boon. Bio-technology has changed the way, a patient with seizure disorder is being monitored and managed at a befitting epilepsy centre all around the world [13].

One such technology is mobile health \& wearable device to detect seizures at earliest point of time, in terms of altered neuronal electrophysiology, sometimes even before the actual seizure is noticeable by the patient or the accompanying person. These devices are mobile health apparatus worn by the patients during their routine daily activities. Patients can have them attached to their body during stay at home, during office hours, while commuting in public places or even while jogging in the park. This is entirely dissimilar to the conventional and cumbersome Video-EEG (V-EEG) labs where electrodes are applied to the skull of the patient and connected to monitors, obviously necessitating admission to hospital. Unfamiliarly with these network of wires with his/her head makes the patient feel anxious \& nervous.

There are 2 broad mechanisms that are used for detection of seizure by these mobile and wearable devices. These are either EEG based or Non-EEG Based. Prototype of EEG based device is Scalp EEG [4]. Surface EMG (Electromyography) [5], movementbased detection [6] and multimodal seizure detection constitutes non-EEG based technologies. Multimodal monitoring methods [7] are non-EEG based techniques that include but not restricted to contact sensors such as accelerometers, electromyography, heart rate, electro-dermal activity, and oximetry. Remote sensors included video, radar, movement, and sound sensors. Video-EEG is considered as the gold standard against which all these devices/ sensors can be evaluated. Each method has its own advantages and limitations.

Overall advantages of mobile and wearable devices in management of epilepsy patients are manifold. Foremost of them is prompt detection of seizure activity \& prevention of Sudden unexpected death in epilepsy (SUDEP) [8]. Secondly, effectiveness of Anti-epileptic drugs (AEDs) in field can also be tested with more reliability. This is possible only due to continuous monitoring of patients in baseline activities within their familiar environment. Mobile health and wearable devices now constitutes an important 
component in management of patients suffering from Drug Resistant Epilepsy. These devices will be helpful in decision making for early referral to epilepsy surgery centre or decision making by epileptologist/neurosurgeon to subject these patients for surgical intervention at an earlier phase in their illness when such intervention is much helpful. Future of such mobile health \& wearable devices will parallel the leading way in which these patients will be managed.

\section{References}

1. Beniczky S, Polster T, Kjaer TW, Hjalgrim H (2013) Detection of generalized tonic-clonic seizures by a wireless wrist accelerometer: a prospective, multicenter study. Epilepsia 54: e58-e61.

2. Onorati F, Regalia G, Caborni C, Migliorini M, Bender D, et al. (2017) Multicenter clinical assessment of improved wearable multimodal convulsive seizure detectors. Epilepsia 58(11): 1870-1879.

\section{ISSN: 2574-1241}

DOI: 10.26717/BJSTR.2018.07.001451

Jitender Chaturvedi. Biomed J Sci \& Tech Res

(C) (i) This work is licensed under Creative

Submission Link: https://biomedres.us/submit-manuscript.php
3. Beniczky S, Conradsen I, Henning O, Fabricius M, Wolf P, et al. (2018) Automated real-time detection of tonic-clonic seizures using a wearable EMG device. Neurology 90(5): e428-e434.

4. Baumgartner C, Koren JP (2018) Seizure detection using scalp-EEG. Epilepsia 59(Suppl 1): 14-22.

5. Beniczky S, Conradsen I, Wolf P (2018) Detection of convulsive seizures using surface electromyography. Epilepsia 59(Suppl 1): 23-29.

6. Arends JBAM (2018) Movement-based seizure detection. Epilepsia 59(Suppl 1): 30-35

7. Leijten FSS (2018) on behalf of the Dutch Tele Epilepsy Consortium. Multimodal seizure detection-a review. Epilepsia 59 (Suppl 1): 42-47.

8. Ryvlin P, Ciumas C, Wisniewski I, Beniczky S (2018) Wearable devices for sudden unexpected death in epilepsy prevention. Epilepsia 59(Suppl 1): 61-66.

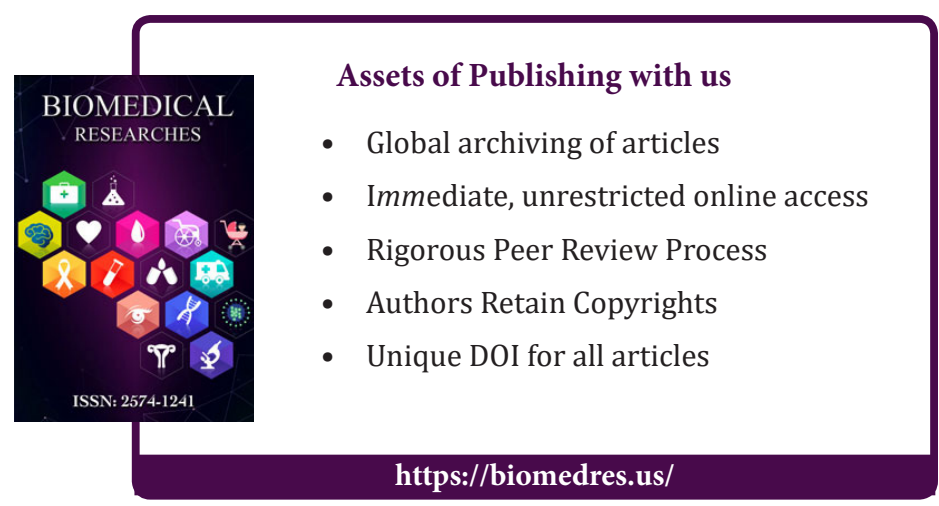

